\title{
Thermohydrologic Behavior at the Potential Yucca Mountain Nuclear Waste Repository
}

T.A. Buscheck, N.D. Rosenberg, Y. Sun and J. Gansemer

February 17, 2000

U.S. Department of Energy

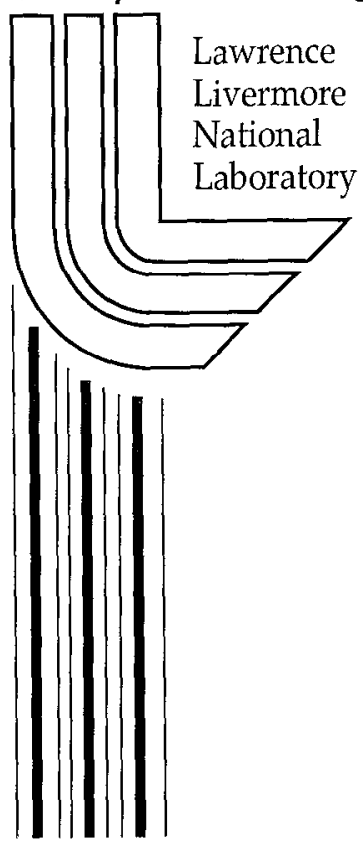




\section{DISCLAIMER}

This document was prepared as an account of work sponsored by an agency of the United States Government. Neither the United States Government nor the University of California nor any of their employees, makes any warranty, express or implicd, or assumes any legal liability or responsibility for the accuracy, completeness, or usefulness of any information, apparatus, product, or process disclosed, or represents that its use would not infringe privately owned rights. Reference herein to any specific commercial product, process, or service by trade name, trademark, manufacturer, or otherwise, does not neccssarily constitute or imply its endorsement, recommendation, or favoring by the United States Government or the University of California. The views and opinions of authors expressed herein do not necessarily state or reflect those of the United States Government or the University of California, and shall not be used for advertising or product endorsement purposes.

Work performed under the auspices of the U. S. Department of Energy by the University of California Lawrence Livermore National Laboratory under Contract W-7405-Eng-48.

This report has been reproduced

directly from the best available copy.

Available to DOE and DOE contractors from the

Office of Scientific and Technical Information

P.O. Box 62, Oak Ridge, TN 37831

Prices available from (423) 576-8401

http://apollo.osti.gov/bridge/

Available to the public from the

National Technical Information Service

U.S. Department of Commerce

5285 Port Royal Rd.,

Springfield, VA 22161

http://www.ntis.gov/

OR

Lawrence Livermore National Laboratory

Technical Information Department's Digital Library

http://www.llnl.gov/tid/Library.html 


\section{Thermohydrologic Behavior at the Potential Yucca Mountain Nuclear Waste Repository}

Thomas A. Buscheck

Nina D. Rosenberg

Yunwei Sun

Jim Gansemer 


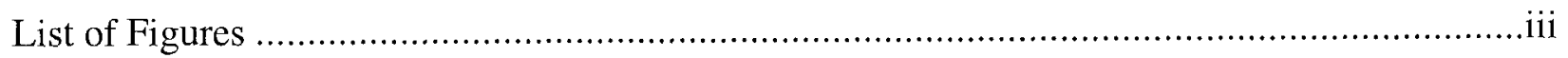

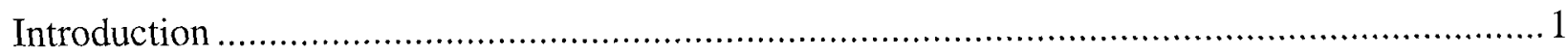

Thermohydrologic Processes at Yucca Mountain ....................................................... 1

Thermohydrologic Issues Affecting Repository Design Selection .................................... 3

Thermal Design Issues and Key System Performance Variables..................................... 3

Engineering Design Variables that Affect Heating Conditions ....................................5

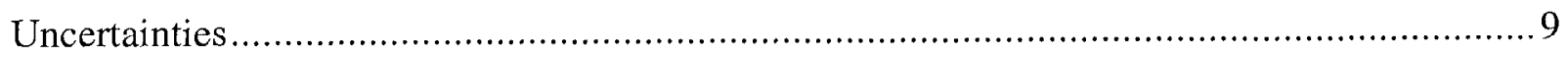

Variability of Response Across Repository ........................................................ 9

Thermohydrologic System Response to Thermal Loading ............................................ 10

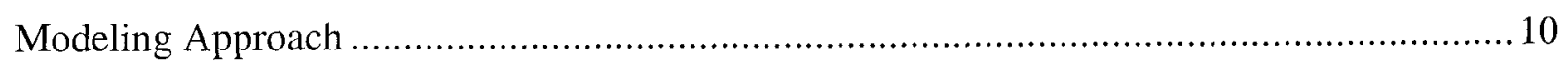

Thermal Design, Thermohydrologic Behavior and System Performance ......................... 12

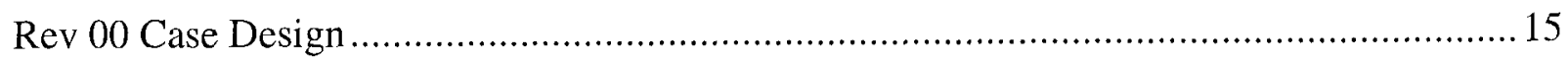

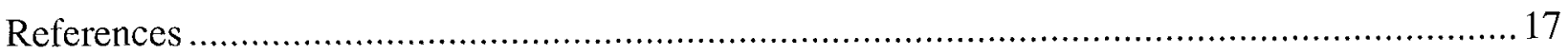




\section{List of Figures}

Fig 1. Relationship between $R H$ reduction and temperature differential.

Fig 2. CCDFs for peak waste package and drift wall temperatures for LADS designs.

Fig 3. CCDFs of $R H$ reduction for LADS designs.

Fig 4. CCDFs of boiling zone extent and duration for LADS designs.

Fig 5. CCDFs for waste package and drift wall peak temperatures for Rev 00 design.

Fig 6. CCDFs of $R H$ reduction for Rev 00 design.

Fig 7. CCDFs of boiling zone extent and duration for Rev00 design.

Fig 8. CCDFs of $R H$ reduction for designs with different backfill. 


\section{Introduction}

Radioactive decay of high-level nuclear waste emplaced in a Yucca Mountain repository will produce an initial heat flux on the order of 30 to 50 times the heat flux in the Geysers geothermal reservoir in California (Hardin et al., 1998). Even though the rate of heat production decreases rapidly with time after emplacement, this heat flux will change the thermal and hydrologic environment, affecting both the host rock and conditions within the drifts in ways significant to key repository performance variables.

\section{Thermohydrologic Processes at Yucca Mountain}

Under ambient conditions, liquid-phase flow in the repository host rock arises as a result of the infiltration of rainfall and snowmelt. Nlthough most of the total fluid-storage capacity is contained in the matrix pores of this rock, the permeability in the matrix is very low (upwards to six orders of magnitude less than that of the fractures in the repository host rock) and fractures dominate liquid-phase flow. After the emplacement of nuclear waste, the thermally-driven transport of water vapor away from the heat source causes a redistribution of the pore fluids within a potentially large volume of rock; depending on the thermal design of the repository, this volume can extend from the ground surface to some distance below the water table and over an area larger than the repository footprint. Water in the matrix pores evaporates, creating dryout zones around the emplacement drifts and condensation zones outside of the dryout zones. The generation of steam replaces air within the boiling zone, reducing the gas-phase mass fraction of air almost to zero for a period of time.

The initial movement of water vapor is within the matrix pores. Once the decay-heat-driven water vapor has entered a fracture network, the direction of flow is generally away from the heat source; however, if the fracture permeability is high enough, buoyant gas-phase convection can cause water vapor movement to be predominantly upwards in the vicinity of the emplacement drifts. Depending on the thermal design of the repository and the fracture permeability, vapor flow within fractures occurs over length scales of several meters to hundreds of meters.

Decay heat is transported away from the emplacement drifts (in the rock mass) by conductive and convective heat-transfer mechanisms. Thermal conduction is the dominant heat-transfer 
mechanism in the rock mass. Thermal radiation is the dominant heat-transfer mechanism within the open spaces inside the emplacement drifts. The transport of water vapor results in much greater heat transport than does liquid-phase flow. Two important heat-transfer mechanisms involving the transport of water vapor are heat pipes and buoyant gas-phase convection. Heat pipes result from vapor transport away from the heat source and gravity-driven and/or capillarydriven condensate flow back towards the heat source (i.e., refluxing). Buoyant gas-phase convection results from mass-density gradients driven by temperature gradients in the rock mass. Depending on the thermal design of the repository, this mechanism (which may occur at the drift and at mountain scales) can increase the buildup of condensate above the repository.

The thermohydrologic behavior of the repository can be divided into three sequential periods: drying, steady-state, and rewetting. 'The concept of these three periods is applicable over dynamically changing spatial regimes in addition to temporal regimes. At a given time, certain locations in a repository may have already progressed to the rewetting regime while other locations remain in the drying regime. During the drying and steady-state periods, liquid-phase flux in the refluxing zone dominates over local percolation flux.

In the host rock, local thermohydrologic behavior is dominated by whether that location is inside or outside of the zone of boiling temperatures. Therefore, the spatial and temporal extent of the boiling zone is very important. Although thermohydrologic processes such as evaporation occur at below-boiling temperatures, the most important processes (i.e., refluxing and dryout) require temperatures being at the boiling point of water. Note that the boiling temperature can be higher than the nominal boiling temperature $\left(96^{\circ} \mathrm{C}\right)$ at the repository horizon. The key aspects of the system are (1) boiling-period duration and (2) whether boiling-period temperatures are high enough to be indicative of superheated conditions or are indicative of refluxing/ heat-pipe conditions.

Two important factors influence the thermohydrologic conditions within the emplacement drift. Whether or not temperatures at the drift wall are above the boiling point strongly affects the likelihood of water seeping into the drift. If the local heat flux at the drift wall is greater than the product of the local liquid-phase flux and the heat of evaporation, then water cannot seep into the drift. If the converse is true, then seepage into the drift is possible. The temperature gradient 
between the waste package and drift wall strongly affects how much lower the relative humidity $R H$ on the waste package is than at the drift wall.

\section{Thermohydrologic Issues Affecting Repository Design Selection}

\section{Thermal Design Issues and Key System Performance Variables}

The repository design selection process involves tradeoffs between competing goals, including performance, economic costs, uncertainty and constructability. Thermal design goals include:

- Keeping temperatures below critical temperatures for engineered materials.

- Keeping waste packages dry (i.e., low $R H$ ) until cool.

- Limiting water seeping onto waste packages.

- Limiting the spatial extent of boiling conditions in host rock.

The first goal listed above concerns limiting the temperature-dependent degradation of key engineered barrier system (EBS) components, such as the zircoloy cladding of the spent nuclear fuel rods in the waste packages. Critical temperatures for engineered materials are materialdependent, but are general upwards of $300^{\circ} \mathrm{C}$. In general, the greater the local heat generation rate, the hotter the waste package will become. Since backfill acts as insulation, a design with backfill will result in waste package temperatures greater than an otherwise equivalent design without backfill.

The second goal listed above concerns limiting degradational mechanisms that are enhanced with the presence of liquid films at elevated temperatures. Ambient conditions at the repository horizon are very humid $(R H>99 \%)$. Depending on the repository design, $R H$ on waste packages can be significantly less than ambient for an extended period of time. Keeping waste packages dry until cool translates to maintaining conditions of reduced $R H(<80-90 \%)$ as long as possible. Because temperatures continuously decline with time, maximizing the duration of reduced $R H$ translates to minimizing the temperature once humid conditions are attained on the waste packages.

Repository engineered materials are susceptible to electrochemical corrosion processes at temperatures above approximately $80-90^{\circ} \mathrm{C}$. Even though the environment in the repository 
drifts at these temperatures is expected to be dry, there is concern that thin films of brine could exist on the component surfaces. Brines could form on these surfaces through evaporation of water that seeps into the drift, or by water adsorption by hygroscopic salts directly deposited on these components, from previous evaporation events or from particulates that enter the drifts. The latter is of concern because the deliquescence point of some salts is above the boiling point for water, which could result in brine formation at above-boiling temperatures, and the higher the temperature, the greater the corrosion potential.

There are three primary factors that contribute to reducing $R H$ on waste packages. The first primary factor is whether EBS components, such as backfill and drip shields (which overlie waste packages), are included in the design. These components insulate the waste package from the drift wall, thereby enhancing the temperature difference between the drift wall and the waste package. In an open drift (i.e., with nothing separating the waste package from the drift wall), the temperature difference between the waste package and drift wall is controlled by thermal radiation. Because thermal radiation is an extremely efficient heat-transfer mechanism, this results in a small temperature difference. Because the temperature difference between the waste package and drift wall reduces $R H$ on the waste package with respect to the drift wall (Fig. 1), it can be beneficial to insulate the waste package from the drift wall with the use of a low-thermalconductivity backfill. A drip shield overlying the waste package will act as a thermal radiation shield, thereby enhancing the temperature difference between the waste package and drift wall. The second primary factor contributing to $R H$ reduction on waste packages is the presence of above-boiling conditions in the host rock (rock dryout) at the drift-wall boundary. Dryout of the host rock results in $R H$ reduction in the host rock and in the drift (and on waste packages). Generally, the waste package can be no more humid than the rock at the drift wall. Rock dryout also limits the tendency for water to seep into the drift. Minimizing the seepage flux into the drift maximizes the benefit of the temperature difference between the waste package and drift wall on $R H$ reduction on waste packages.

The third primary factor contributing to $R H$ reduction is limiting the tendency for water to seep into the drift. This can be accomplished in two ways. As mentioned above, keeping the drift wall above the boiling point will limit the tendency for seepage. After boiling has ceased at the drift wall, seepage can be limited by EBS designs that minimize wicking of water into the drift 
and promote drainage of any water that does seep into the drift. Wicking of water into the drift can be limited if a low-capillarity backfill is used; such a backfill material will also promote rapid drainage of any water that does seep into the drift.

The third goal listed above, limiting water contacting waste packages, concerns limiting the potential for radionuclide relcase and transport in the event that waste packages are breached. There are several ways to limit water contact onto waste packages. One way is to reduce potential seepage into the drift by maintaining above-boiling conditions at the drift-wall boundary. A second way is by utilizing EBS designs that minimize wicking of water into the drift and promote drainage of any water that does seep into the drift.

The fourth goal listed above concerns limiting the uncertainty that arises from the hard-to-assess potential effects of coupled thermal-hydrologic-chemical (THC) and thermal-hydrologicmechanical (THM) behavior in the host rock; these processes challenge current abilities to predict system response. Some changes, such as fracture closure due to thermal-mechanical stresses, may be temporary; others, such as the mineral alteration in fractures from thermochemical processes, may be permanent.

These four thermal-design goals are interdependent. For example, backfill may be used to keep relative humidity low, but may make peak waste packages too hot. Similarly the reduction in uncertainty that comes from limiting boiling-conditions, comes at the cost of a loss in $R H$ reduction in the drifts due to decreased rock dryout.

\section{Engineering Design Variables that Affect Heating Conditions}

The primary thermal-design variables that affect thermohydrologic behavior in the repository are (1) areal mass loading, (2) lineal mass loading, (3) spent fuel age, (4) waste package spacing and sequencing, (5) duration and heat-removal efficiency of drift ventilation, and (6) engineered barrier system (EBS) design (e.g., whether backfill or drip shields are emplaced).

Areal Mass Loading (AML), expressed in metric tons of uranium per acre, is a measure of the overall heat-generation density of waste inventory. The AML is the key factor determining the magnitude of long-term thermohydrologic effects, including the radial and vertical extent of boiling in the host rock and the duration of boiling conditions in the emplacement drifts. 
Lineal Mass Loading (LML), expressed in metric tons of uranium per meter of emplacement drift, is a measure of the average heat-generation density along the drifts. The LML is the key factor determining short-lerm thermohydrologic effects, such as the peak temperatures on waste packages and on the drift wall, and the temperature difference between the waste package and drift wall.

Spent-Fuel Age, expressed in years, quantifies how long since the spent-fuel assembly has been removed from the nuclear reactor core. Because the heat generation rate decays with time, younger spent fuel has a higher thermal power output than does older spent fuel. Spent-fuel age is a key factor determining short-term thermohydrologic effects, such as peak temperatures on waste packages and on the drift wall. Above-ground storage of spent fuel prior to emplacement in the repository will lower the peak temperatures.

Waste-package spacing and heat-source heterogeneity determine the variability of thermohydrologic conditions along drifts. Waste-package spacing pertains to the end-to-end distance between waste packages. If waste packages are spaced far apart from each other along the drift ( "point-load" waste-package spacing), heating conditions along the drift will be highly heterogeneous. If the waste packages are spaced nearly end to end ( "line-load" waste-package spacing), the line of waste packages will act like a homogeneous line-source of heat. With respect to thermal power output there are two primary classes of waste packages: (1) commercial spent-nuclear fuel (CSNF) and (2) all other waste-package types, including defense high-level waste (DSNF) and high-level waste (HLW). The CSNF waste packages generate much more heat than non-CSNF waste packages; thermal output from CSNF waste packages also declines much more slowly with time. Fuel blending (the mixing and matching of waste package of different thermal power) can be used to reduce the heat-source heterogeneity along the drift. However, because of the large difference in thermal output between CSNF and non-CSNF waste packages, there is a limit to the effectiveness of fuel blending in reducing heat-source heterogeneity.

Duration and heat-removal efficiency of drift ventilation strongly affect thermohydrologic conditions during the pre-closure period; they can also continue to affect thermohydrologic conditions for hundreds of years after ventilation has ceased. Drifts can be ventilated up to the end of the pre-closure period. The percentage of heat removed from the repository system (heat- 
removal efficiency) increases with ventilation flow rate. The long-term effects of drift ventilation on thermohydrologic conditions increase with ventilation duration and heat-removal efficiency. As a thermal-management measure, drift ventilation is used to limit peak temperatures on waste packages and drift wall surfaces, and boiling conditions in the host rock Engineered barrier system (EBS) design can have a dominant effect on thermohydrologic conditions in the drifts for tens of thousands of years. The EBS design does not influence overall heating conditions in the near-field host rock; however, it can influence the symmetry of heating conditions around the perimeter of the drift.

The most important consideration is whether backfill is emplaced. In an open drift, thermal radiation results in a symmetric heat-flux distribution around the perimeter of the drift wall, resulting in a uniform temperature distribution around the drift. Because thermal radiation is a very efficient heat-transfer mechanism, it also results in a very small temperature gradient $\Delta T$ between the waste packages and the drift wall. The presence of backfill causes thermal conduction to replace thermal radiation as the dominant heat-transfer mechanism in the drift, resulting in a much greater $\Delta T$ between the waste package and drift wall, which translates to a hotter waste package with lower $R H$. The thermal conductivity and thickness of the backfill, along with the local heat-generation rate, determines the magnitude of $\Delta T$. The hydrologic parameters of the backfill determine the how much water from the host rock might be wicked into the drift due to capillary forces. (Backfill also serves the very important non-thermal function of protecting the waste packages from rockfall.) Many different backfill designs are possible, including single-layer backfill and multiple layers of backfill that function as a capillary barriers. Another important component that may be included in the EBS design are drip shields that drape over the top and around the sides of waste packages.

There are a large number of combinations of the various thermal-design variables described above. Fortunately, the most significant aspects of the thermohydrologic response of Yucca Mountain to thermal loading from radioactive waste can be described to first order by considered only a few major attributes.

- Whether boiling or sub-boiling conditions occur in the host rock. A sub-boiling thermal design will not result in rock dryout, which reduces the duration of significant $R H$ reduction on waste package. The potential benefit of a sub-boiling design is that uncertainty may be 
reduced due to the decreased need to understand and model the potential effects of coupled THC and THM behavior in the host rock.

- Whether or not the boiling zones around individual drifts coalesce. Rock dryout gencrally increases with increascd arcal mass loading, but if the thermal design results in coalescence of the boiling zones, a significant condensate zone can develop above the repository. When the repository begins to cool and rewetting begins, this condensate will increase the percolation flux above the repository horizon. If the thermal design does not result in coalescence of boiling zones, condensate will be able to drain continuously between the drifts, obviating the possibility of significant condensate buildup above the repository.

- Heterogeneity of heating along drifts. Line-load waste-package spacing results in more intense, localized, and persistent near-field rock dryout around the drifts and more efficient condensate shedding between the drifts. Point-load waste-package spacing results in less intense near-field rock dryout and more heterogencous thermohydrologic conditions along the drifts. This heterogeneity makes it more likely for seepage and condensate within the drift to be focused onto cooler waste packages.

- Whether backfill is used and the material properties of the backfill. The two most important material properties are thermal conductivity and capillarity. The emplacement of backfill will increase $\Delta T$ between the waste package and drift wall compared to the case without backfill. The magnitude will depend on the thermal conductivity. The larger $\Delta T$ results in greater $R H$ reduction on the waste package relative to the drift wall (Fig. 1). A low-capillarity backfill reduces the tendency for capillary wicking into the drift and facilitates rapid drainage of water that does seep into the drift. Minimizing the presence of water in the drift allows for the maximum benefit of $\Delta T$ on $R H$ reduction on waste packages. A high-capillarity backfill facilitates capillary wicking into the drift obviating the $R H$ reducing benefits of $\Delta T$. Once wicking has caused the backfill to reach a steady-state liquidphase saturation state, $R H$ reduction is no longer significant; therefore a high-capillarity backfill will always result in the temperature increase (relative to the no backfill case) but eventually will not provide $R H$ reduction on waste packages. 


\section{Uncertainties}

In addition to the engineering design variables there are uncertainties in the natural system. The two major ones are uncertainties in rock properties values in repository horizon rock and infiltration flux. The key rock properties of concern are those hydrologic properties governing capillarity (i.e., matrix imbibition and capillary wicking in fractures) and thermal conductivity. In addition to parameter uncertainty, there are uncertainties in our ability to understand and predict unsaturated flow processes in fractured rock under ambient conditions and to coupled THC and THM behavior.

\section{Variability of Response Across Repository}

The thermohydrologic environment that will arise as a result of the emplacement of heatproducing radioactive waste is influenced by a number of key factors:

- Infiltration flux. Infiltration flux varies significantly over the repository footprint. The fluxes are greatest at the crest of Yucca Mountain and lowest along the flanks and in the alluvial-filled washes.

- Hydrologic properties in the repository horizon host-rock unit. The most important properties are those governing capillarity, most importantly in the host rock unit. The capillary properties of the matrix govern how quickly matrix imbibition rewets the dryout zone. The capillary properties of the fractures affects the tendency for water to seep or wick (if backfill is used) into the drift.

- Edge-cooling effect. Cooling increases with proximity to the edge of the repository, reducing the duration of rock dryout significantly. (Note that it is possible to take advantage of this phenomenon by placing the hotter waste packages at the edges.)

- Overburden thickness. The depth of the repository horizon below the ground surface translates to thickness of insulating rock between the repository and the ground surface, a constant-temperature boundary, which acts like a heat sink. If the repository is close to horizontal, the repository depth contours correspond to the surface topography.

- Thermal properties in the repository horizon host-rock unit. The repository intersects several different subunits of the Topopah Springs Tuff, subunits which have different enough thermal conductivity values to be significant. 


\section{Thermohydrologic System Response to Thermal Loading}

\section{Modeling Approach}

A multiscale modeling approach is used to assess repository performance for various repository designs. The need for a multiscale modeling approach stems from the fact that the performance measures depend on thermohydrologic behavior within a few meters of the emplacement drifts and also on thermal and thermohydrologic behavior on a repository (or mountain) scale. A single numerical model (e.g., embedding a 3-D drift-scale model with a relatively fine mesh into a 3-D mountain-scale model with a coarse mesh) would require an unfeasible number (millions) of grid blocks. The Multiscale Thermohydrologic Model (MSTHM) has been developed for estimating the results that would be obtained if such a single model were possible (Buscheck et al., 1998). In addition to coupling the drift scale and mountain scale, the MSTHM also allows for consideration of the effect of different waste packages types (e.g., different CSNF waste packages, co-disposal of defense HLW) on the various performance measures.

The Multiscale Thermohydrologic Model consists of four major submodels and includes multiple scales (mountain and drift), multiple dimensions (1-D, 2-D and 3-D) and varying assumptions regarding the coupling of heat transfer to fluid flow (conduction-only and fully coupled thermohydrologic). These four submodels are:

- LDTH (Line-averaged-heat-source, Drift-scale, Thermohydrologic) Submodel

- SMT (Smeared-heat-source, Mountain-scale, Thermal-conduction) Submodel

- SDT (Smeared-heat-source, Drift-scale Thermal-conduction) Submodel

- DDT (Discrete-heat-source, Drift-scale Thermal-conduction) Submodel

It is useful to think of the LDTH submodel as the "core" submodel. These 2-D drift-scale TH submodels are run for locations spaced evenly throughout the repository area (31 locations in the latest model implementation) for several Areal Mass Loading (AML) values (nominal value and lower) to represent the influence of edge-cooling effects. The LDTH submodel includes the hydrologic processes and parameters (e.g., surface infiltration rates, hydrologic properties) used to describe a location, given specific coordinates within the repository. 
The remaining three submodels, which are conduction only, are required to account for the influence of 3-D mountain-scale heat flow and 3-D drift-scale heat flow on drift-scale TH behavior. The coupling of 3-D mountain-scale heat flow to 2-D drift-scale TH behavior is accomplished with the SMT and the SDT submodels. The SMT submodel is 3-D and includes the influence of thermal property variation in the mountain, lateral heat loss at the repository edges, and overburden-thickness variation with location, assuming a uniform, planar (i.e., smeared) heat source throughout the repository area. The SMT submodel accounts for the actual shape and location of the repository footprint in Yucca Mountain. The SDT submodel is a 1-D (vertical) submodel, run at the same 31 locations and for the same AMLs as the LDTH submodels. To obtain the "line-averaged" drift-wall temperature (which is roughly equivalent to an average waste package location), the relationship between the drift-wall temperature in the LDTH submodel and the "smeared" repository-plane temperature in the SDT submodel is used modify the temperatures in the SMT submodel, thereby resulting in an MSTHM drift-wall temperature that approximates the effects of the most important TH processes at the drift-scale and the geometry effects of the mountain scale. At this stage of the MSTHM abstraction methodology, the influence of 3-D drift-scale heat flow has not yet been added.

Because the SM'I and SD'l submodels both share the same smeared-heat-source approximation and thermal conduction representation of heat flow, the relationship between the SDT submodel temperature and the LDTH submodel drift-wall temperature allows for the SMT submodel temperature to be "corrected" for both the influence of TH processes on temperature and for the influence of 2-D drift-scale dimensionality (orthogonal to the axis of the drift). The SMT, SDT, and LDTH submodels all share a blended heat-generation history, which blends the heatgeneration histories of the entire waste package repository; hence, the heat-generation history is effectively that of an "average" waste package. The DDT submodel is a 3-D drift-scale submodel which includes individual waste packages (with distinctive heat-generation histories) and accounts for thermal radiation in addition to thermal conduction between the waste packages and drift surfaces. The drift-wall temperatures for an average waste package, calculated with the combined use of the LDTH, SMT and SDT submodels, are then further modified to account for waste-package-specific deviations using the DDT submodel. This is accomplished by relationships between local temperatures at various "point" locations along the drift (such as on 
the drift wall, drip shield surface, and waste package surface) and the corresponding "lineaveraged" temperature in the DDT submodel.

The results of the MSTHM submodels are integrated with the use of the Multiscale Thermohydrologic Abstraction Code (MSTHAC). Details are described in CRWMS M\&O (2000).

\section{Thermal Design, Thermohydrologic Behavior and System Performance}

Seven repository designs were evaluated as part of the License Application Design Selection (LADS) study (Buscheck, 1999). A comparison of key performance variables for these designs illustrates many of the concepts described in previous sections. The seven designs considered described below.

- EDA I: A low thermal load (areal mass loading [AML] = $45 \mathrm{MTU} / \mathrm{acre}$ ) is used, along with point-load waste-package spacing, 25 years of waste aging, blending of fuel assemblies, and 25 years of ventilation of the emplacement drifts. Drift spacing is $44.1 \mathrm{~m}$. These thermal management measures prevent the rock and all waste packages from ever reaching the boiling point of water. Ventilation is assumed to reduce the decay-heat generation rate from waste packages by $50 \%$ during the entire 25 -year preclosure period.

- EDA IIa: An intermediate thermal load (AML = $60 \mathrm{MTU} / \mathrm{acre}$ ) is used, along with line-load waste-package spacing, blending of fuel assemblies, and 50 years of drift ventilation. These thermal management measures prevent coalescence of the boiling zones and promotes drainage of condensate and infiltration flux between drifts. Low-capillarity backfill is emplaced at 50 year. Ventilation is assumed to reduce the decay-heat generation rate from waste packages by $50 \%$ during the entire 50-year preclosure period. Drift spacing is $81.5 \mathrm{~m}$.

- EDA IIh: This is the same as EDA IIa, except with no backfill.

- EDA IIc: This is the same as EDA IIa, except that the assumption of 50 years of ventilation is replaced with the assumption of 25 years of surface aging, followed by 25 years of drift ventilation. Low-capillarity backfill is emplaced after 25 years.

- EDA III: This design uses a higher thermal load (AML = 85 MTU/acre), a line-load wastepackage spacing and 50 year of drift ventilation to promote the drainage of condensate and 
infiltration flux between drifts. Ventilation is assumed to reduce the decay-heat generation rate from waste packages by $50 \%$ during the entire 50 -yearr preclosure period.

- EDA IV: This is the same as EDA III, except that sand backfill is emplaced after 50 years. Drift spacing is $56.6 \mathrm{~m}$.

- EDA V: A high thermal load (AML = 170 MTU/acre), along with line-load waste-package spacing, 25 year waste aging, and 75 year of drift ventilation, is used to prolong the duration of rock dry-out and $R H$ reduction on waste packages. Because a much smaller repository area is required, the repository can be located entirely in an area of the repository with low infiltration flux. Ventilation is assumed to reduce the decay-heat generation rate from waste packages by $50 \%$ during the entire 75 -year preclosure period. Drift spacing is $32.6 \mathrm{~m}$.

Modeling results from simulations of these seven designs are shown in Figs. 2-4. Each of these plots is presented as a complementary cumulative distribution function (CCDF) of all waste packages types at all repository locations where thermohydrologic variables were evaluated. In this analysis, eight different waste packages were considered, including various commercial spent nuclear fuel (e.g., pressurized-water reactors, boiling-water reactors) and defense highlevel waste and each of these eight waste packages types was evaluated at 431 repository locations, a total of 3448 different values in all ( $8 \times 431)$. Results are shown for a present-dayclimate infiltration flux scenario.

Fig. 2 shows the peak temperatures on the waste packages and the drift wall (averaged around drift perimeter) for all seven designs. Peak temperatures for EDA I are all below boiling point; all other designs have peak temperatures above boiling point. The addition of backfill causes a significant increase in peak temperature on waste packages, while causing a minimal increase on the drift wall. Aging and fuel blending both help to lower peak temperatures by tens of degrees. Prolonged ventilation period in EDA V allows an extended period of boiling without high peak temperatures.

Fig. 3 shows the time and temperature when waste packages first see $R H$ levels of $80 \%$ (following the temperature peak). For EDA I, the duration of reduced $R H$ on waste packages is extremely short . For designs without backfill, the duration of $R H$ reduction on waste packages increases with increasing rock-dryout duration and with increasing boiling duration; all three of these durations increase with increasing AML. For designs with backfill, the duration of reduced 
$R H$ is much greater than for the cases without backfill. For the backfill cases, reduced $R H$ occurs long after boiling ceases, while for the cases without backfill, reduced $R H$ does not persist long after the end of the boiling period.

The temperature when the waste packages first see $R H=80 \%$ increases with increasing AML in all above-boiling designs. This trend results from the higher AML cases resulting in a more persistent coalesced boiling zone that causes a larger condensation zone above the repository. The coalesced boiling zone thwarts the ability of both condensate flux and percolation flux to drain through (or around) the repository. During the period that the boiling zone is coalesced, much of the percolation flux is trapped above the repository. Without the presence of the coalesced boiling zone, this percolation flux would have drained through the repository horizon. Thus, both condensate and percolation are trapped above the boiling zone, causing a substantial buildup of liquid-phase in the upper condensate zone. The liquid-phase saturation buildup above the repository increases the percolation flux above the repository horizon during the rewetting period, which decreases the time required to rewet the dryout zone. Because the uncoalesced boiling zones generated by EDA II allow for the continuous drainage of percolation flux and condensate through the repository horizon, there is negligible liquid-phase saturation buildup above the repository. Consequently, EDA II rewets more slowly following the end of the boiling period than do any of the higher AML designs (EDAs III, IV, and V). The slower rewetting for EDA II results in a lower temperature when waste packages first see $R H=80 \%$.

Fig. 4a shows the time required for the drift wall to return to the nominal boiling point (which is $96^{\circ} \mathrm{C}$ at the repository horizon elevation) after peak-drift temperatures have occurred. Fig. $4 \mathrm{~b}$ shows the maximum lateral extent of the boiling zone in host rock at the plane of the waste packages. The maximum lateral extent of boiling is a good indication of spatial extent of rock dryout around the emplacement drifts. For EDA I, which remains sub-boiling, the CCDF is a straight line at 0 and the extent of boiling is $0 \mathrm{~m}$. For EDA III, IV and $\mathrm{V}$, the boiling zones coalesce; therefore, the maximum lateral extent is equal to the half-drift spacing.

Since the presence or absence of coalesced boiling zones is so important to evaluating repository performance to thermal loading, it is useful to note that without ventilation or surface aging of spent nuclear fuel, $\Lambda \mathrm{MLs}$ greater than $70 \mathrm{MTU} / \mathrm{acre}$ generally result in coalesccd boiling zones. The AML used in the Viability Assessment design, 85 MTU/acre, resulted in upwards to $5000 \mathrm{yr}$ 
of boiling conditions at the center of the repository (CRWMS M\&O, 1998). The AML used in the Site Recommendation Rev 00 design, 60 MTU/acre, results in uncoalesced cylindrical boiling zones (Buscheck, 1999). This thermohydrologic response of the system to the Rev 00 design are described in more detail in the next section.

\section{Rev 00 Case Design}

\section{Brief Description}

The Rev 00 design is for a 60-MTU/acre repository with 5.5-m-diameter drifts spaced 81 meters apart. The design assumes no above-ground aging of the waste and the continuous ventilation of the emplacement drifts during the entire 50-yr pre-closure period. The requirement for drift ventilation is to remove $70 \%$ of the waste heat from the entire emplaced waste inventory. At the end of the pre-closure period, drip shields are placed over the waste packages; this is followed by the emplacement of fine-grained (high capillarity) sand backfill over the top and around the sides of the drip shield.

The thermal management strategy for this design was to prevent coalescence of the boiling zones and to promote the continuous drainage of condensate and percolation flux between drifts. The Rev 00 case design is very similar to the EDA IIa design described earlier. The major difference from a thermal system performance point of view is the material properties of the backfill. Details of the Rev 00 design are provided in CRWMS M\&O (2000). Although most of the parameters assumed for the LADS study discussed above also hold for the Rev 00 analysis, it is important to note that some parameters did change. For example, the initial line-averaged heatgeneration rate along the drifts increased substantially from the LADS analysis to the Rev 00 analysis.

Modeling results from simulations of the Rev 00 design are shown in Figs. 5-7. These plots are analogous to those presented earlier for the LADS study designs. Several infiltration rates were considered representing low, mean and high infiltration-flux cases. Also, 623 repository locations were considered for this analysis.

Fig. 5 shows the peak temperatures on the waste packages and the drift wall (again, averaged around the drift-wall perimeter) for the three infiltration rates considered. During the pre-closure period, temperatures at the drift wall remain below the boiling point for the mean and high 
infiltration flux cases, while temperatures climb above the boiling for the low flux case. Peak waste package temperatures of $96-100^{\circ} \mathrm{C}$ occur at $10-25$ years. Edge-cooling effects do not strongly affect pre-closure temperatures. During the post-closure period, the highest peak waste package temperature is $315^{\circ} \mathrm{C}$ (for the low flux case) and this temperature occurs at 60 years. The difference in peak waste package temperature between the hottest and coldest waste package is on the order of $40^{\circ} \mathrm{C}$. Due to the asymmetric distribution of insulating backfill around the waste package, which focuses much of the heat generation from the waste package to the floor of the drift, peak temperatures on the lower drift wall are up to nearly $70^{\circ} \mathrm{C}$ hotter than at the upper drift wall. By 100 years, the influence of edge cooling is considerable, with waste package temperatures varying by $120^{\circ} \mathrm{C}$ from the repository edge to the center of the repository.

Fig. 6 shows the time and temperature when waste packages first see $R H$ levels of $85 \%$ (following the temperature peak). As was discussed earlier, $R H$ on waste package depends on three quantities: (1) $R H$ at the drift wall, (2) the temperature difference between the drip shield and drift wall (which reduces $R H$ at the drip shield relative to the drift wall), and (3) the temperature difference between the waste package and drip shield (which reduces $R H$ at the waste package relative to the drip shield). The $R H$ reduction at the drift wall decreases strongly with proximity to the edge of the repository due to reduced rock dryout. Significant reduction in $R H$ at the drift wall persists for about 100 to 1000 years for the mean and high infiltration-flux cases and for about 200 to 2000 years for the low infiltration-flux case. The $R H$ reduction on the drip shield and waste packages is a function of intra-drift temperature gradients. Eventually, $R H$ on the drip shield becomes nearly $100 \%$. For the mean and high infiltration-flux cases this takes about 1000 to $2000 \mathrm{yr}$ and for the low infiltration-flux case about 3000 to $6000 \mathrm{yr}$ to occur. The $R H$ reduction on the waste package persists long after $R H$ reduction on the drip shield has ceased.

Fig. 7a shows the time required for the drift wall to return to the nominal boiling point after peak temperatures have occurred. Fig. $7 \mathrm{~b}$ shows the maximum lateral extent of boiling zone in the host rock at the plane of the waste packages. Note that the maximum lateral extent of boiling is considerably greater for the low infiltration-flux case than for the mean or high flux cases. For the median waste package location, the maximum lateral extent of boiling is between $8.4-10.5 \mathrm{~m}$ depending on infiltration flux. For the hottest (and driest) waste-package location, the maximum 
percentage of the rock pillar separating drifts that can be driven to the boiling point lies between $24 \%$ and $44.4 \%$.

As discussed earlier, the hydrologic properties of the backfill material play a critical role in system performance. Fig. 8 compares $R I I$ reduction between the Rev 00 design with highcapillarity backfill and the EDA IIa design with low-capillarity backfill discussed earlier. In the Rev 00 design, as the temperature at the drift wall declines below the boiling point, water is able to wick by capillary flow from the fractures in the host rock into the backfill. This wicking by the backfill results in the "capturing" of flow from host rock fractures over a region that is wider than the footprint of the drift. Capillary wicking in the backfill, in conjunction with the duration of boiling temperatures at the drift wall, influences the onset of seepage into the drift. As Fig. 8 clearly shows, the low-capillarity backfill in the EDA IIa design results in significantly greater $R H$ reduction than the high-capillary backfill in the Rev 00 design. Other possible backfill designs, such as a two-layer capillary barrier, may result in even greater $R H$ reduction. 


\section{References}

Buscheck, T. A, J. Gansemer, J.J. Nitao, and T.H. Delorenzo 1998. "Multi-Scale Near-Field Thermohydrologic Analysis of Alternative Designs for the Potential Repository at Yucca Mountain" Wronkiewicz D.J., and Lee, J.H., eds. Scientific Basis for Nuclear Waste Management XXII. Mater. Res. Soc. Symp. Proc. 556. Warrendale, Pennsylvania: Materials Research Society.

Buscheck, T. A. 1999. Thermohydrologic Calculations for Site Recommendation/License Application Design Selection, Phase 2, UCRL-ID-133988.

CRWMS M\&O 2000. Multiscale Thermohydrologic Model . ANL-EBS-MD-000049, REV 00A.Las Vegas, Nevada.

CRWMS M\&O. 1998. Total System Performance Assessment-Viability Assessment (TSPAVA) Analyses, Technical Basis Document, Chapter 3: Thermal Hydrology. B0000000001717-4301-00003 REV 01. Las Vegas, Nevada: Civilian Radioactive Waste Management System, Management and Operating Contractor: TRW Environmental Safety Systems, Inc. ACC: MOL.19981008.0003.

Hardin, E.L., et al. 1998. Near-Field/Altered-Zone Models Report. Milestone report for the CRWMS Management and Operating Contractor, U.S. Department of Energy. UCRL-ID129179. SP3100M3. Livermore, California: Lawrence Livermore National Laboratory. 


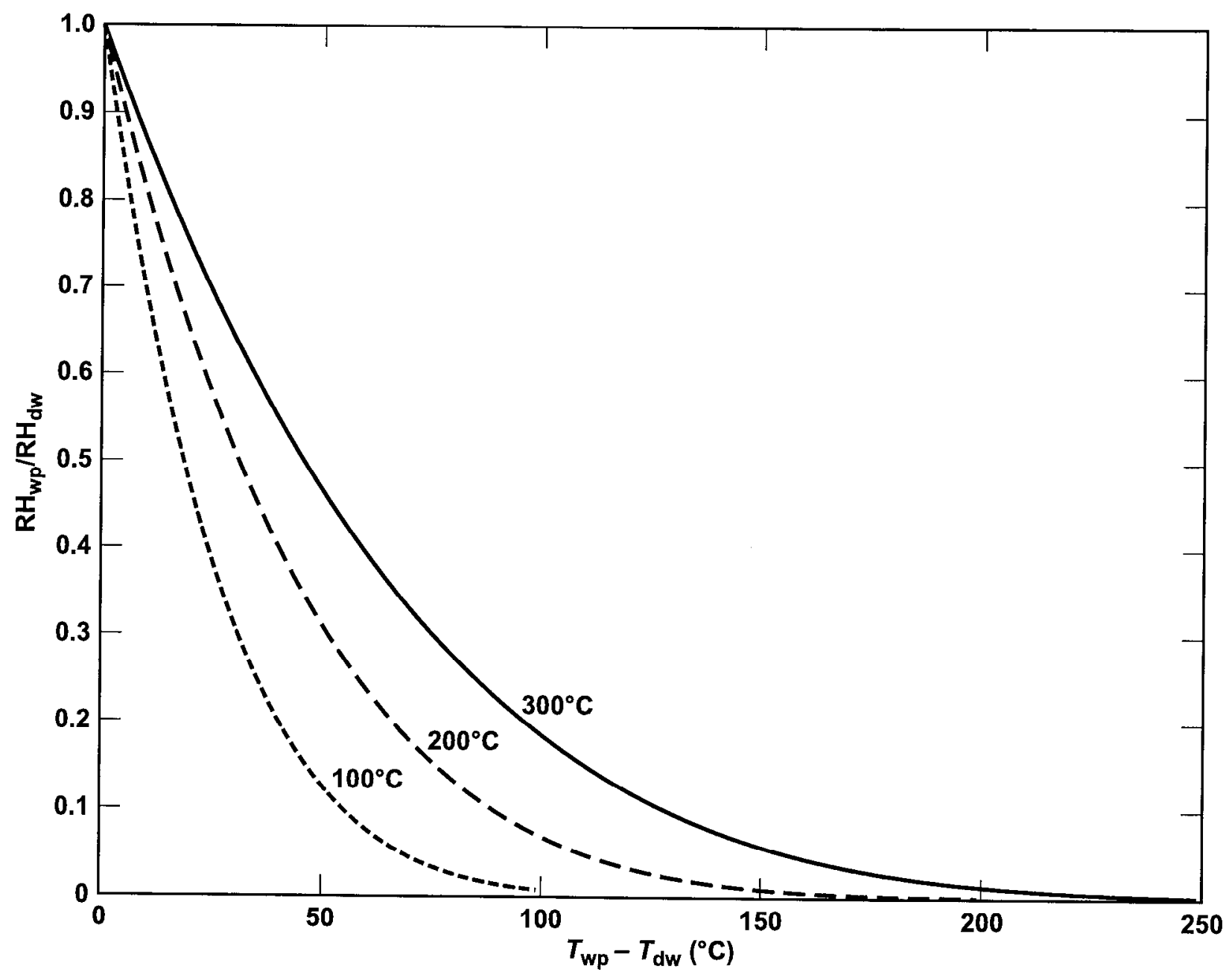

Fig 1. Relationship between $R H$ reduction and temperature differential. Relative humidity $R H$ ratio between waste package and drift wall versus temperature difference between waste package and drift wall for various temperatures. 

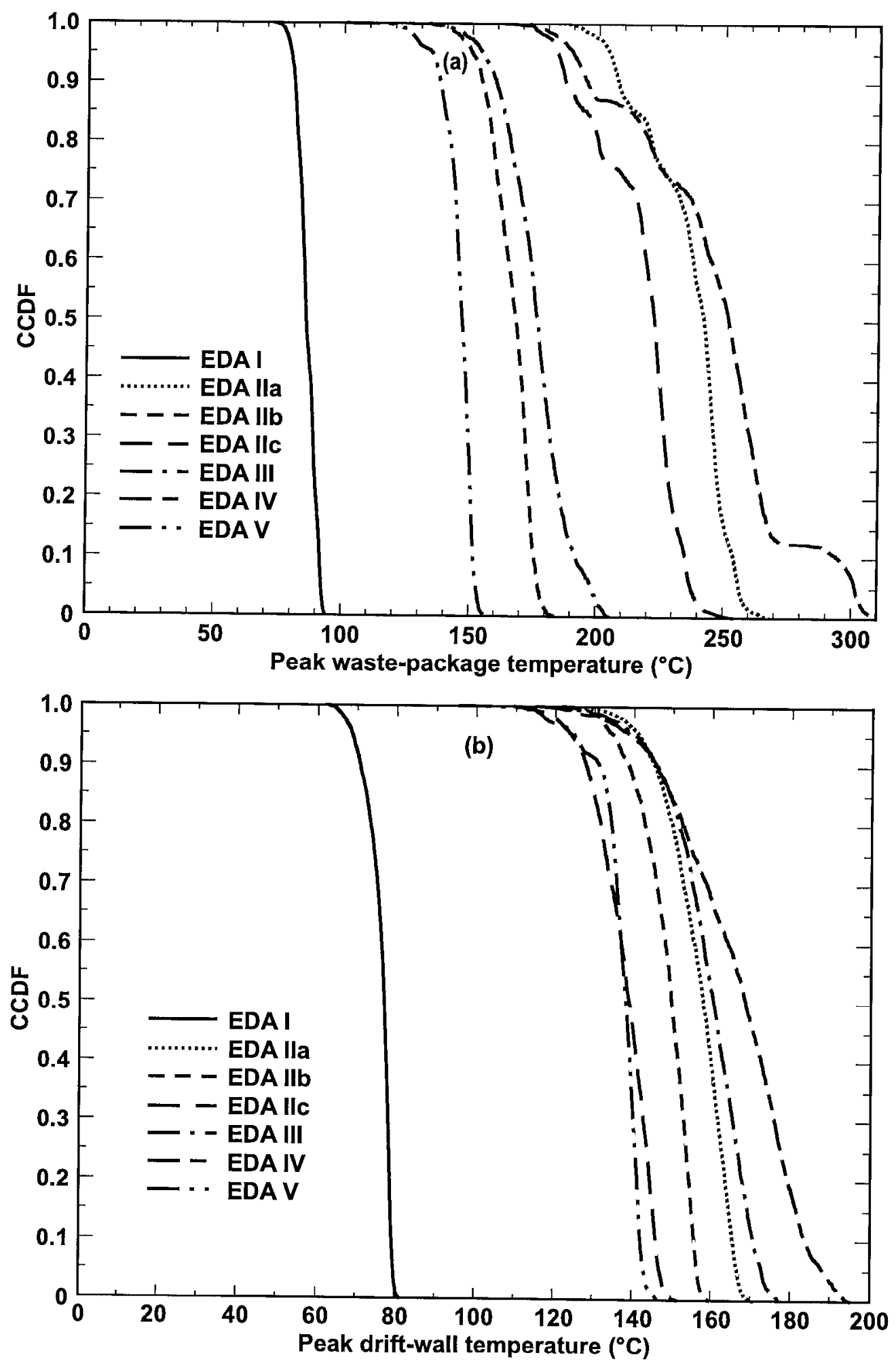

Fig 2. CCDFs for peak waste package and drift wall temperatures for $L \Lambda D S$ designs. (a) Complementary cumulative distribution function (CCDF) of the peak waste package temperature for the nearly 3500 combinations of waste package types and repository location considered for LADS designs; (b) CCDF of the peak drift-wall temperature for the same cases. 

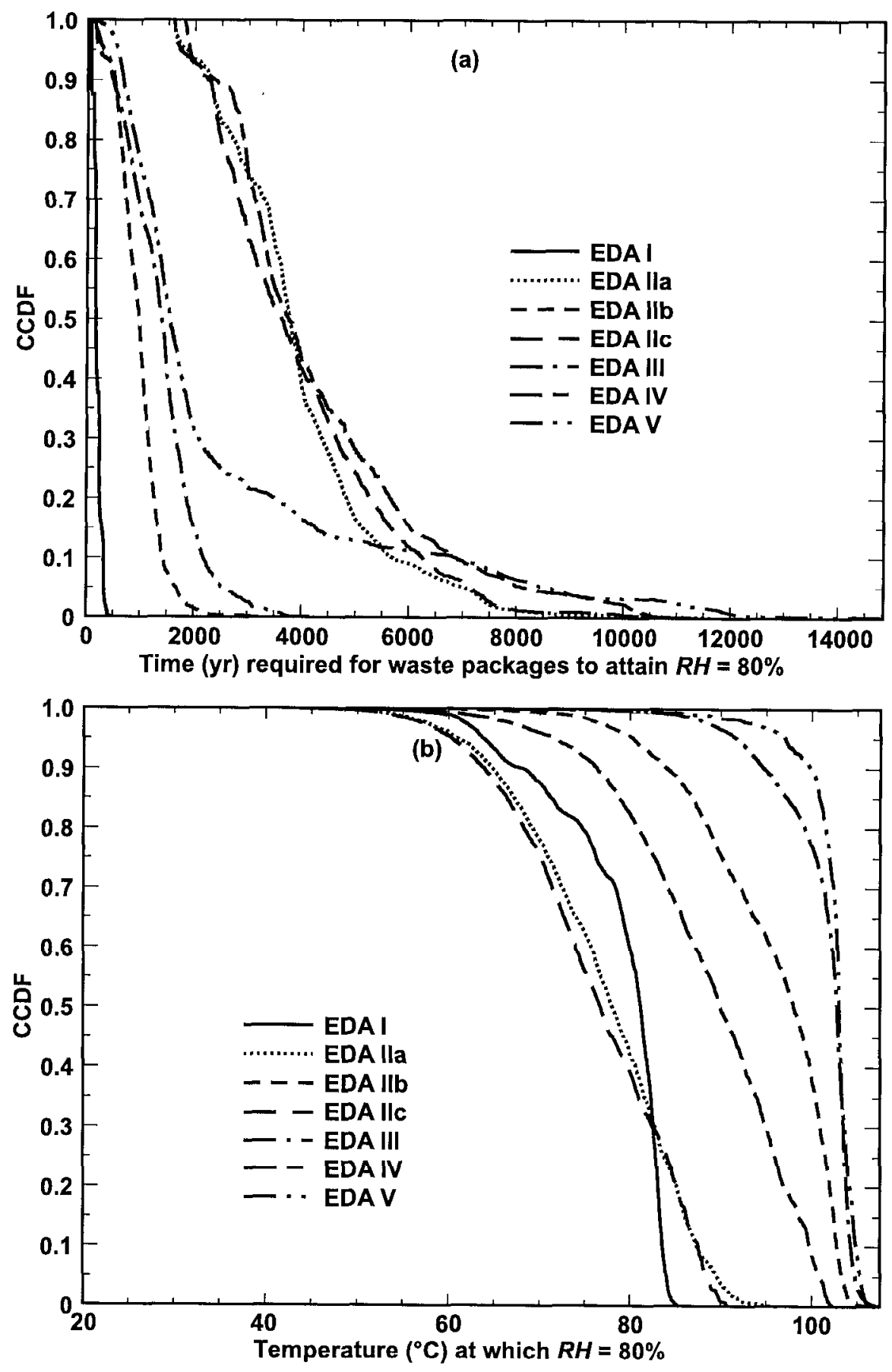

Fig 3. CCDFs of $R H$ reduction for I.ADS designs. (a) Complementary cumulative distribution function (CCDF) for the time required for waste packages to attain a relative humidity $R H$ of $80 \%$ for the nearly 3500 combinations of waste package types and repository location considered for LADS designs; (b) CCDF of the waste package temperature at which waste packages reach an $R H$ of $80 \%$ for the same cases. 

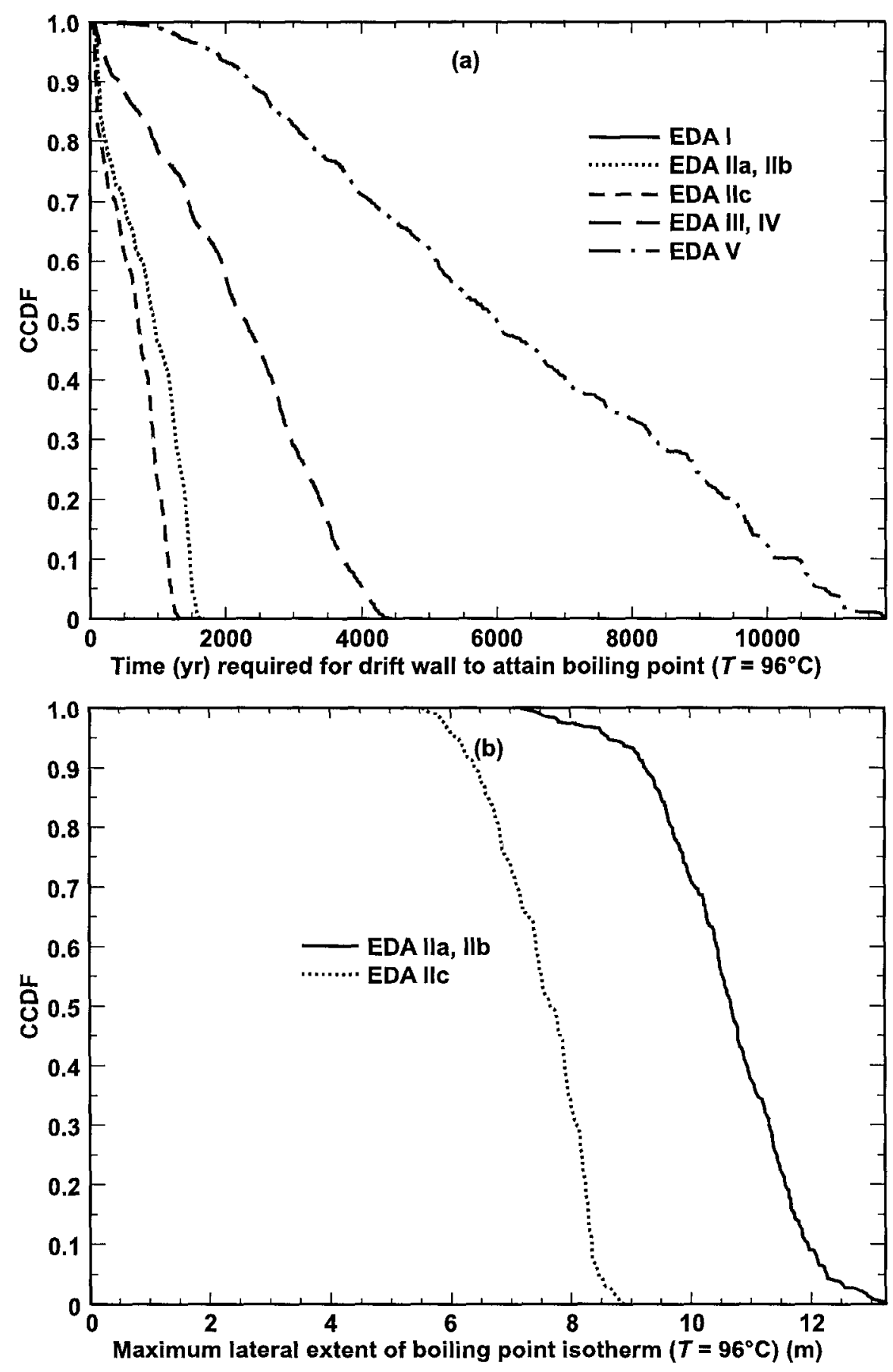

Fig 4. CCDFs of boiling zone extent and duraction for LADS designs. (a) Complementary cumulative distribution function (CCDF) for the time required for the drift wall to attain the boiling-point temperature of $96^{\circ} \mathrm{C}$ during cool-down for the nearly 3500 combinations of waste package types and repository location considered for LADS designs; (b) CCDF of the maximum lateral extent of the boiling-point isotherm. 

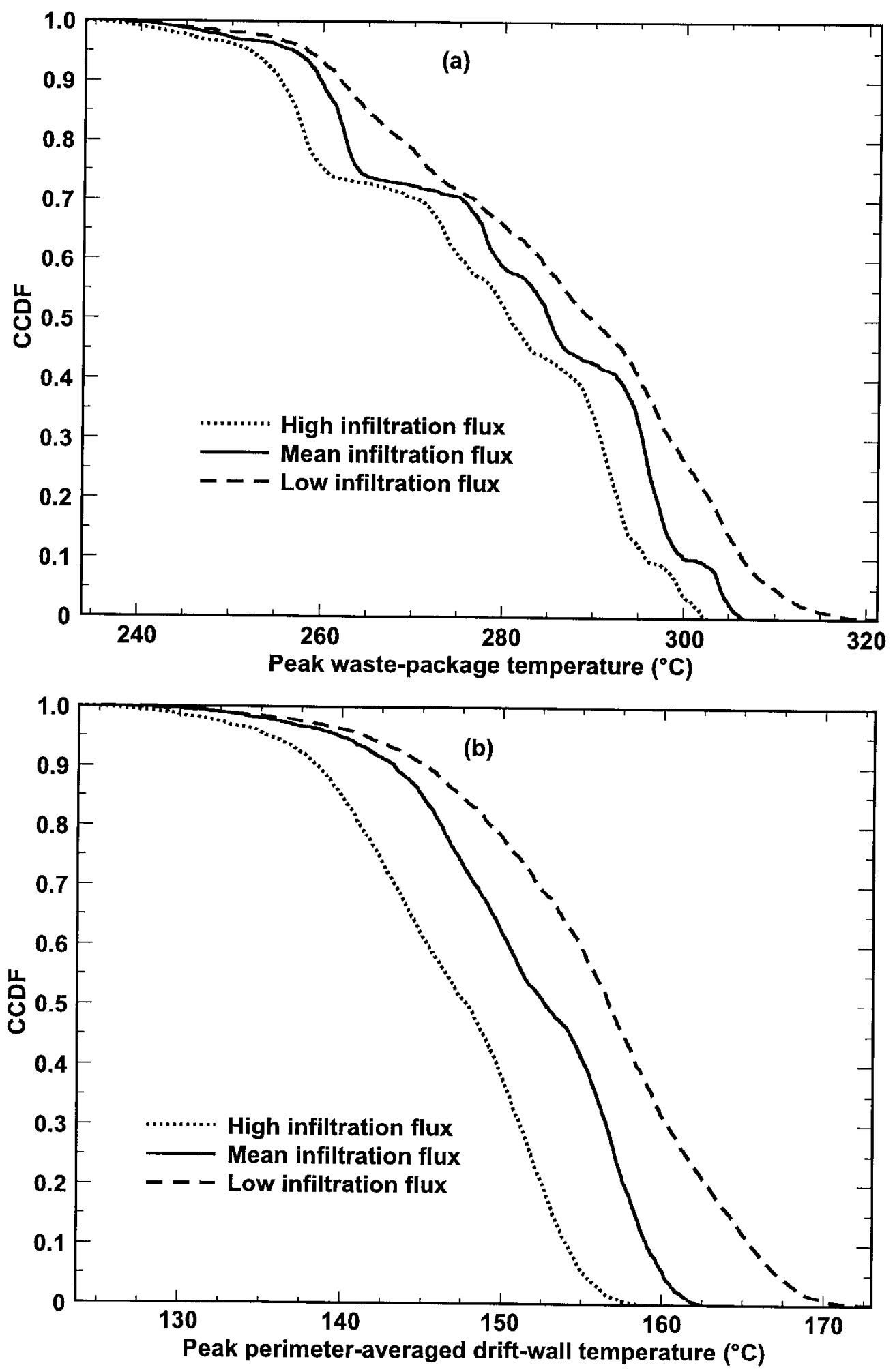

Fig 5. CCDFs for waste package and drift wall peak temperatures for Rev 00 design. (a) CCDF of the peak waste package temperature for the nearly 5000 combinations of waste package types and repository location considered for Rev 00 design, al various infiltration fluxes; (b) CCDF of the peak drift-wall temperature for the same cases. 
(a)

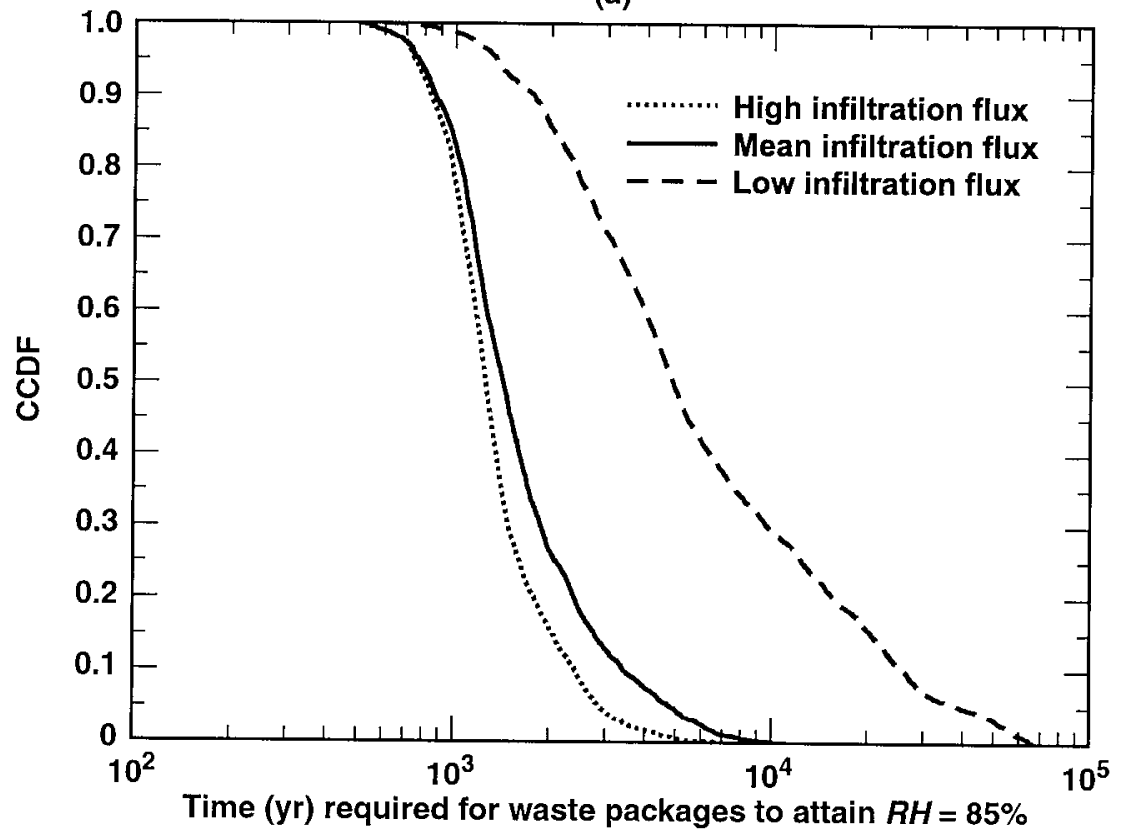

(b)

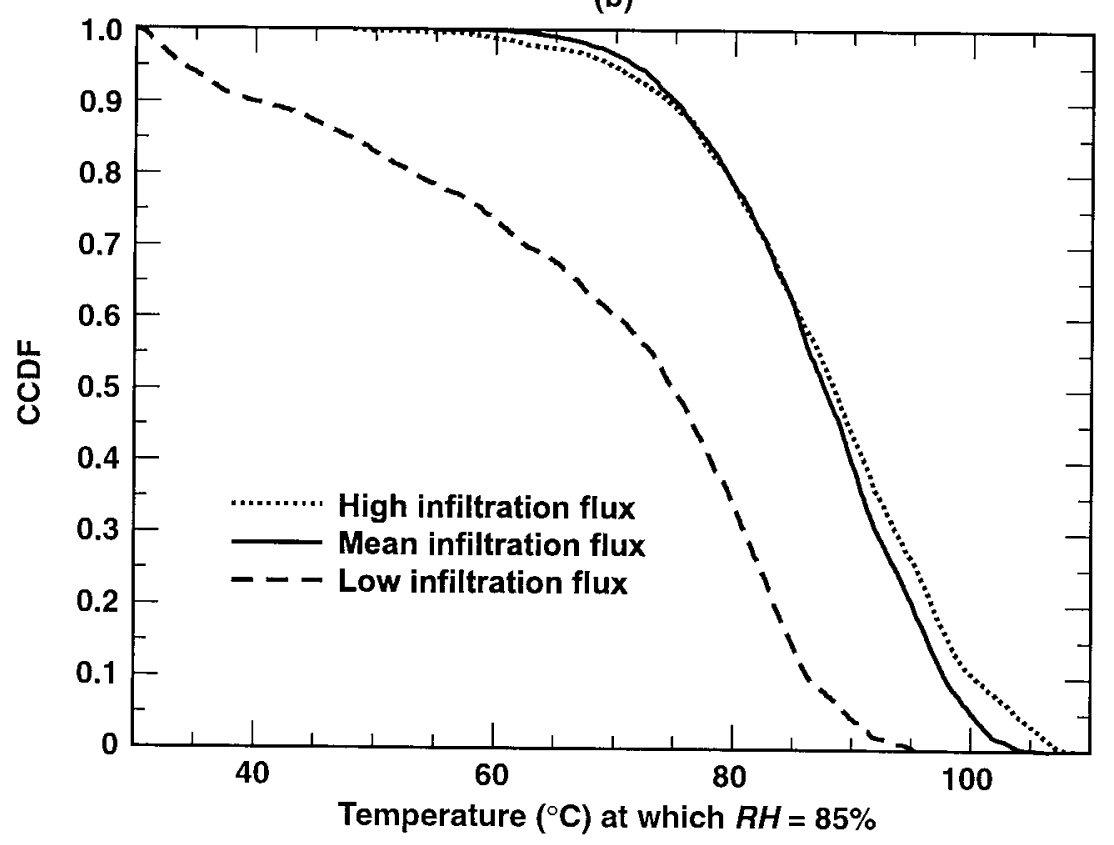

Fig 6. CCDFs of $R H$ reduction for Rev 00 design. (a) Complementary cumulative distribution function $(\mathrm{CCDF})$ for the time required for waste packages to attain a relative humidity $R H$ of $85 \%$ for the nearly 5000 combinations of waste package types and repository location considered for Rev 00 design at various infiltration fluxes fluxes; (b) CCDF of the waste package temperature at which waste packages reach an $R H$ of $85 \%$ for the same cases. 

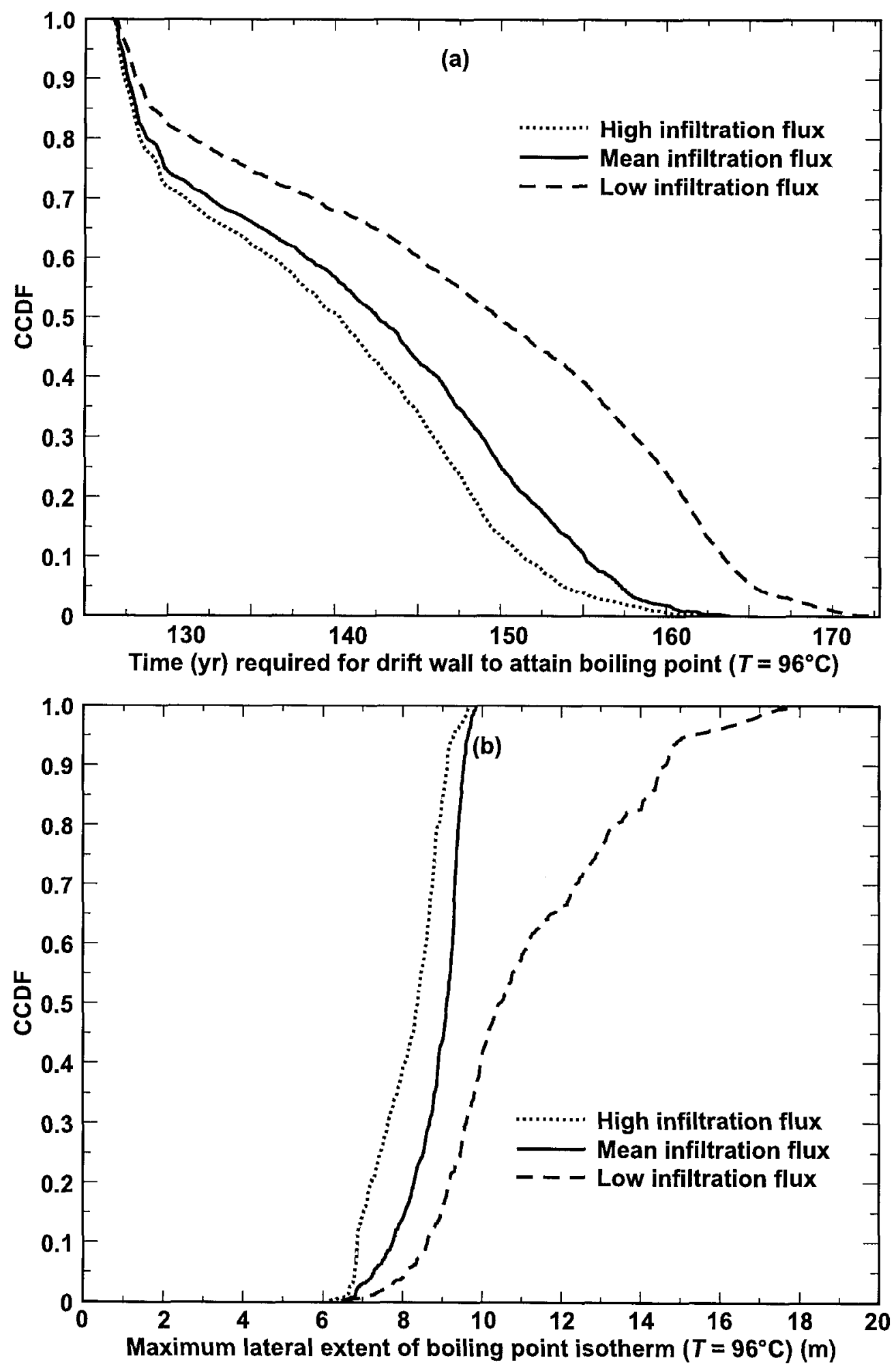

Fig 7. CCDFs of boiling zone extent and duration for Rev00 design. (a) Complementary cumulative distribution function (CCDF) for the time required for the drift wall to attain the boiling-point temperature of $96^{\circ} \mathrm{C}$ during cool-down for Rev 00 design at various infiltration fluxes; (b) CCDF of the maximum lateral extent of the boiling-point isotherm. 

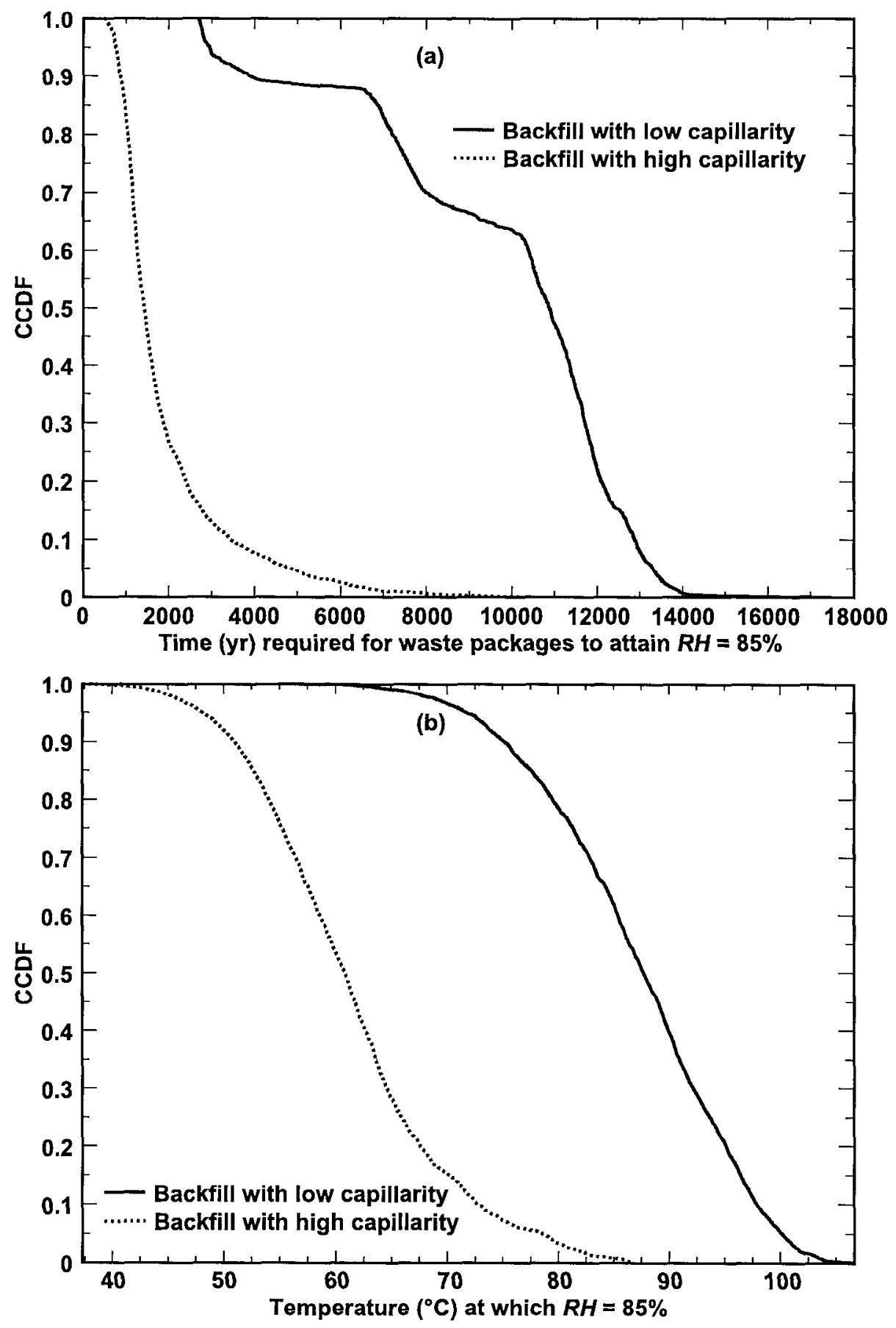

Fig 8. CCDFs of $R H$ reduction for designs with different backfill. (a) Complementary cumulative distribution function (CCDF) for the time required for waste packages to attain a relative humidity $R H$ of $85 \%$ for the LADS EDA IIa design (with low capillarity backfill) and the Rev 00 design (with high capillarity backfill); (b) CCDF of the waste package temperature at which waste packages reach an $R H$ of $85 \%$ for the same cases. 